\title{
Lime composition for the walls of buildings made of aerated concrete
}

\author{
V. I. Loganina ${ }^{1, a^{*}}$, M. V. Frolov ${ }^{1, b}$, Yu. P. Skachkov ${ }^{1, c}$ \\ ${ }^{1}$ Penza State University of Architecture and Construction, Russia, 440028, Penza, Street Titov. 28 \\ aloganin@mail.ru, b mihail-frolovv@yandex.ru, 'offise@pguas.ru
}

Keywords: Aerated concrete, Calcium silicates, Lime, Strength, Structure formation

\begin{abstract}
It is proposed to use for finishing the aerated concrete composition with limy binder. Composition includes limy binder, ground aerated concrete and additives based on a mixture of silicate and calcium aluminum silicates. It has been shown, that the introduction in lime composition ground aerated concrete in an amount of $20 \%$ by weight of the lime can improve the strength of lime composites. It is shown, that the combined use of lime, ground aerated concrete and additives based on a mixture of calcium silicate and silica-alumina allows to obtain limy composition, characterized by an accelerated set of plastic strength. The finishing composition on the basis of the developed formulation is characterized by high water-holding capacity, good workability.
\end{abstract}

\section{Introduction}

The increase of requirements to buildings power efficiency results in the necessity of increase of their heat-shielding. One of ways to solve the given problem is to use a new effective insulating dry building mixes (DBM). In practice for painting and decorating we frequently apply limy DBM. Due to high permeability they provide an optimum microclimate of buildings and constructions. However insufficient water resistance and strength of lime coatings constrain wider application of limy DBM for external furnishings.

An analysis of scientific, technical and patent literature indicates, that for increase resistance coatings on the basis of limy dry building mixes (DBM) in their composition are proposed to introduce the synthesized hydrosilicates of calcium (HSC), silica sol, aluminosilicates, organomineralny additives [1-6].

In the [7] are proposed to use in limy DBM additive based on a mixture of silicate and aluminosilicate of calcium.

It was found, that limy mixture with additive based on a mixture of silicate and aluminosilicate of calcium characterized a more rapid structure formation.

For finish aerated concrete are using different building morter density $1000-1300 \mathrm{~kg} / \mathrm{m}^{3}$. Given the law of the affinity structures, proposed to be produced limy finishing composition with the use of ground aerated concrete, which should lead to an increase in the adhesion to the substrate [8].

\section{Materials and Research Methods}

Technology for producing aluminosilicate additive is in causticization solutions waterglass of calcium hydroxide, followed by reacting the resulting calcium silicate with a solution of aluminum sulphate $\mathrm{Al}_{2}\left(\mathrm{SO}_{4}\right)_{3}[7]$.

For this purpose freshly cooked lime was extinguished the water heated to $60^{\circ} \mathrm{C}$ and brought to boiling. Then in this mix poured in the solution of liquid glass heated to $60^{\circ} \mathrm{C}$, containing $122,4 \mathrm{~g} / 1$ of $\mathrm{SiO}_{2}$ and $47,4 \mathrm{~g} / \mathrm{l}$ of $\mathrm{Na}_{2} \mathrm{O}$. The received pulp was mixed by 15 minutes. The formed deposit was filtered and processed $10 \%$ solution of sulfate of aluminum to $\mathrm{pH}=6,5$. The resulting mixture was filtered and dried at $70^{\circ} \mathrm{C}$ for 12 hours in an drying cabine

Used hydrated lime 2 grade with an activity of $86 \%$, specific surface $S_{\mathrm{sp}}=11800 \mathrm{~cm}^{2} / \mathrm{g}$. Number aerated concrete varied from 0 to $30 \%$ by weight of lime. 
Used hydrated lime 2 grade with an activity of $86 \%$, specific surface $S_{\mathrm{sp}}=11800 \mathrm{~cm}^{2} / \mathrm{g}$. Number aerated concrete varied from 0 to $30 \%$ by weight of lime. Aerated concrete blocks are ground in a ball mill.

Plastic strength or yield stress of the mixture was determined by plastometer KP-3. $\square$ Plastic strength determined by the formula:

$$
\eta=\mathrm{\tau}=\tau_{0}=\mathrm{k} * \frac{\mathrm{P}}{\mathrm{h}^{2}}
$$

where, $\eta$ - plastic strength;

$\tau$ - shear stress;

$\tau_{\mathrm{o}}$ - yield stress;

$\mathrm{k}$ - coefficient depending on the value of the vertex angle of the cone; for the metal cone with an apex angle of $30^{\circ}-\mathrm{k}=1,116$;

$\mathrm{P}$ - the weight of the movable part of the device (load);

$\mathrm{h}$ - depth of immersion of the cone in the mortar mixture.

\section{The Research Results}

XRD data show that the mineralogical composition of the additive presented minerals tobermoritovoy group, gypsum, zeolite [8].

We studied the effect of dosage and fineness of ground aerated concrete on strength composites. Compressive strength limy composites was measured after 28 days of hardening in air-dry conditions at a temperature of $18-20^{\circ} \mathrm{C}$. The results are shown in Fig. 1.

Analysis of experimental data shows, that the introduction of the ground aerated concrete can increase the strength of lime composites. When a dosage of $20 \%$ a maximum growth of strength and depending on the grinding fineness is from 19 to $35 \%$ (Fig. 1). A further increase in dosage ground aerated concrete causes a decrease strength. It was found, that by increasing the specific surface area of the ground aerated concrete compressive strength of the lime composites increases. When the content of ground aerated concrete $20 \%$ by weight of lime and specific surface $S_{\mathrm{sp}}=$ $10820 \mathrm{~cm}^{2} / \mathrm{g}$, a compressive strength of the limy composite is $\mathrm{R}=1,16 \mathrm{MPa}$ (Fig. 1, curve 3 in.). With a specific surface $S_{\mathrm{sp}}=6350 \mathrm{~cm}^{2} / \mathrm{g}$ compressive strength is $1.09 \mathrm{MPa}$ (Fig. 1, curve 2.), and when the specific surface $S_{\mathrm{sp}}=3750 \mathrm{~cm}^{2} / \mathrm{g}$ compressive strength is $1.02 \mathrm{MPa}$ (Fig. 1, curve 1).

Efficiency of application of ground aerated concrete was estimated on change of rheological properties of the lime mixture. The content of ground aerated concrete was to $20 \%$ by weight of lime (Fig. 2).

Analysis plastogramm (Fig. 2) shows, that the mixture of lime with the addition of ground aerated concrete is characterized by a rapid set of plastic strength. So, after 10 hours of mixing of plastic strength composition with the addition of ground aerated concrete with a specific surface $S_{\mathrm{sp}}$ $=3750 \mathrm{~cm}^{2} / \mathrm{g}$ it is $\tau=4,5 \mathrm{kPa}$ (Fig. 2, curve 2), the composition with the addition of ground aerated concrete with a specific surface $6350 \mathrm{~cm}^{2} / \mathrm{g}$ was $\tau=7,0 \mathrm{kPa}$ (Fig. 2, curve 3). Plastic strength control composition was $\tau=0,61 \mathrm{kPa}$ (Fig. 2, curve 1). Increasing the surface area of ground aerated concrete to $S_{\mathrm{sp}}=10820 \mathrm{~cm}^{2} / \mathrm{g}$ leads to more rapid recruitment plastic strength (Fig. 2, curve 4 ) and after 10 hours of mixing it is $\tau=11,74 \mathrm{kPa}$. 


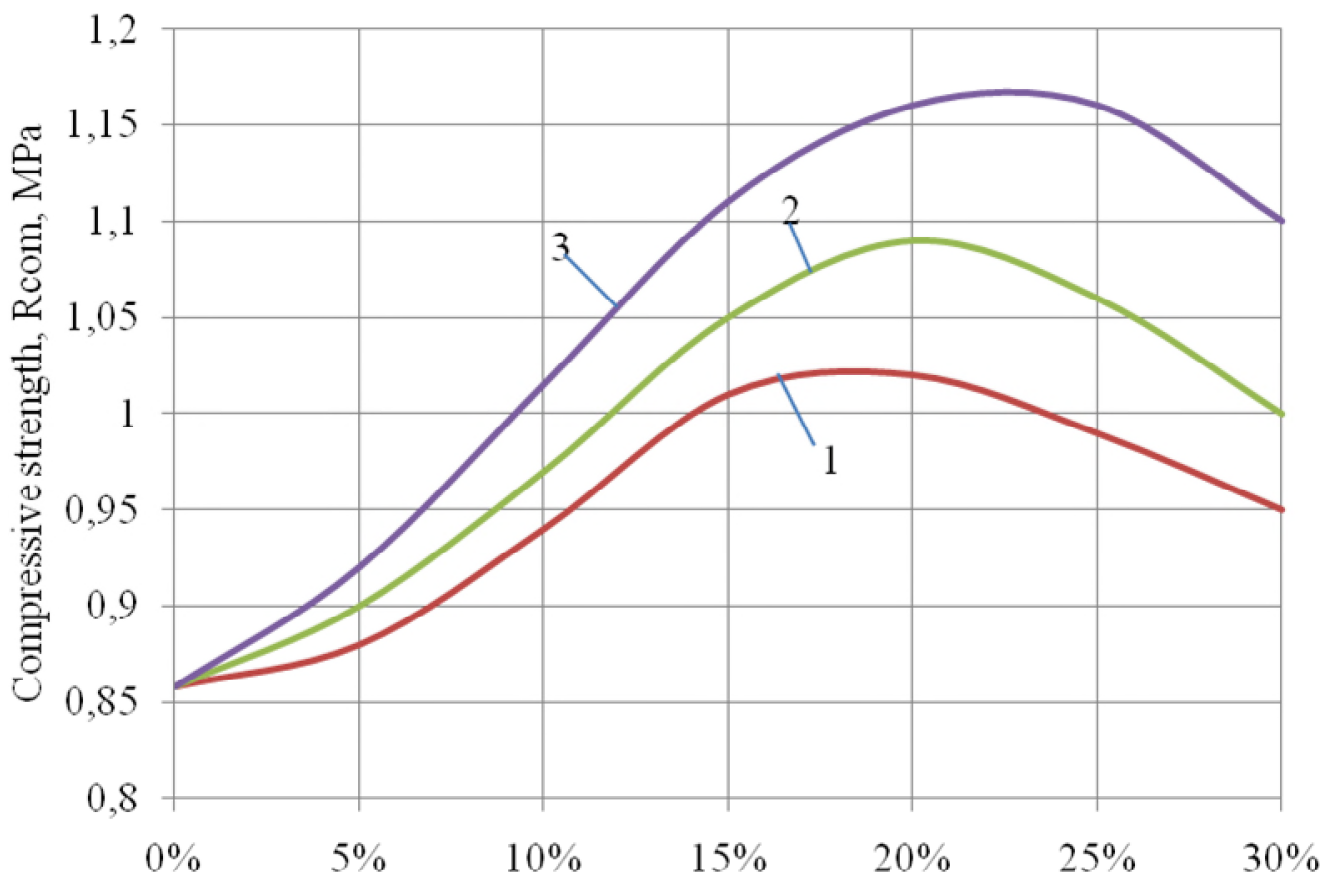

The number of airconcrete. \% bv weight lime

Fig. 1 The dependence of the compressive strength of limy composites from the content of aerated concrete, $\mathrm{W} / \mathrm{L}=1$ :

1 -is the specific surface of the aerated concrete $S_{\mathrm{sp}}=3750 \mathrm{~cm}^{2} / \mathrm{g} ; 2$ is the specific surface of the aerated concrete $S_{\mathrm{sp}}=6350 \mathrm{~cm}^{2} / \mathrm{g} ; 3$ - is the specific surface of the aerated concrete $S_{\mathrm{sp}}=10820$ $\mathrm{cm}^{2} / \mathrm{g}$.

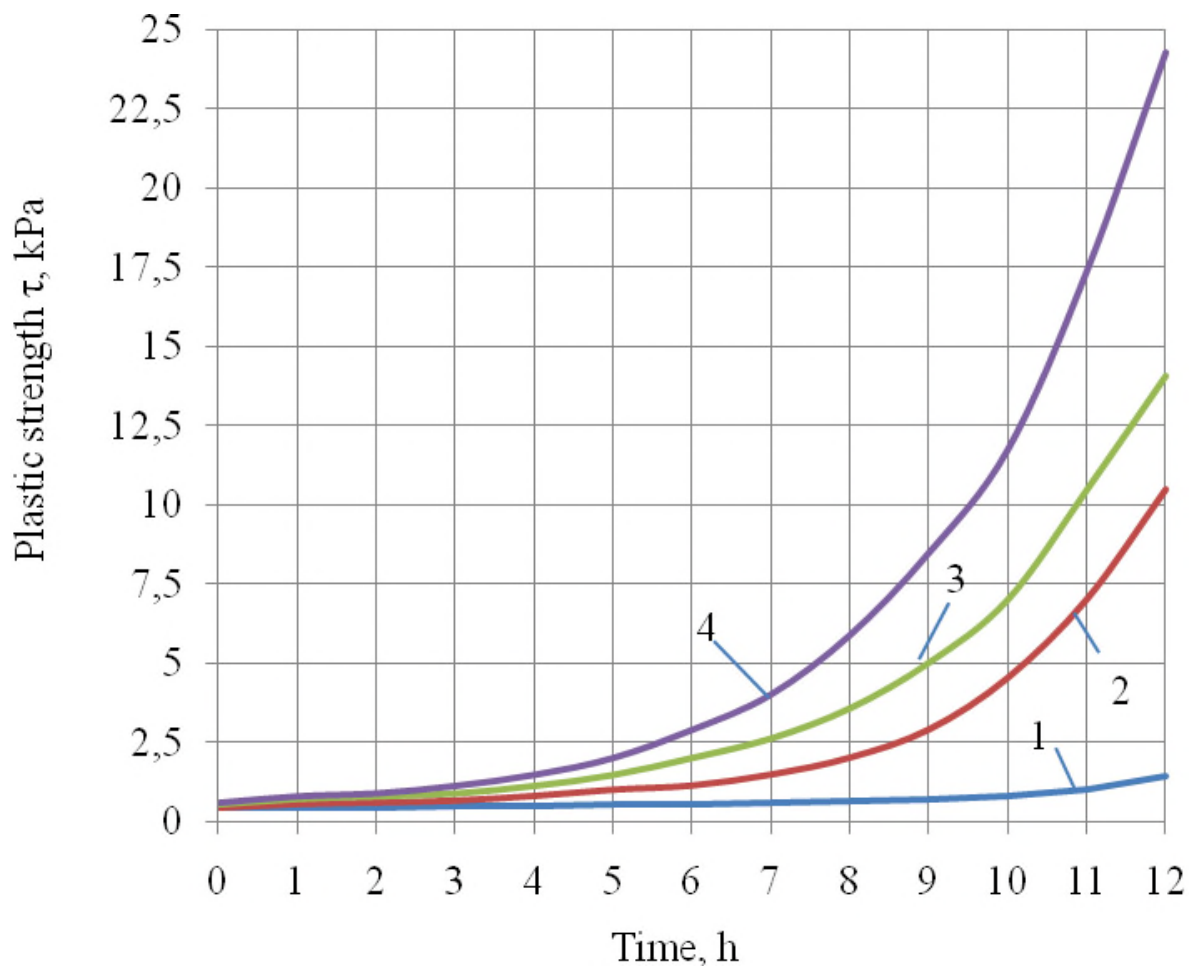

Fig. 2 Change the strength of the plastic limy mixture, W/L = 1: 1 - a control composition on limy binding material; 2 - with the addition of aerated concrete with a specific surface $S_{\mathrm{sp}}=3750 \mathrm{~cm}^{2} / \mathrm{g}$; 3 - with the addition of aerated concrete with a specific surface $S_{\mathrm{sp}}=6350 \mathrm{~cm}^{2} / \mathrm{g} ; 4$ - with the addition of aerated concrete with a surface area $S_{\mathrm{sp}}=10820 \mathrm{~cm}^{2} / \mathrm{g}$. 
There was an increase in initial plastic strength with equal content water. With increasing fineness of grinding aerated concrete increases the strength plastic of lime mixtures. For controlling composition of the value of plastic strength was $\tau=420 \mathrm{~Pa}$, for the composition with the addition of ground aerated concrete with a specific surface $S_{\mathrm{sp}}=3750 \mathrm{~cm}^{2} / \mathrm{g} \tau-=480 \mathrm{~Pa}$, for the composition with the addition of ground aerated concrete with a specific surface $S \mathrm{sp}=6350 \mathrm{~cm}^{2} / \mathrm{g}-\tau=549 \mathrm{~Pa}$, for the composition with the addition of ground aerated concrete with a specific surface $S_{\mathrm{sp}}=10820$ $\mathrm{cm}^{2} / \mathrm{g} \tau=600 \mathrm{~Pa}$. Further aerated concrete with a specific surface $S_{\mathrm{sp}}=6350 \mathrm{~cm}^{2} / \mathrm{g}$ and a dosage of 20 mass\% of lime has been selected. Grinding aerated concrete to a specific surface $S_{\mathrm{sp}}=10280$ $\mathrm{cm}^{2} / \mathrm{g}$ no expedient due to the large amounts of energy.

We studied the combined effect of ground aerated concrete and modifying additive based on a mixture of silicate and aluminosilicate on the properties of lime mortars. The results are shown in Fig. 3.

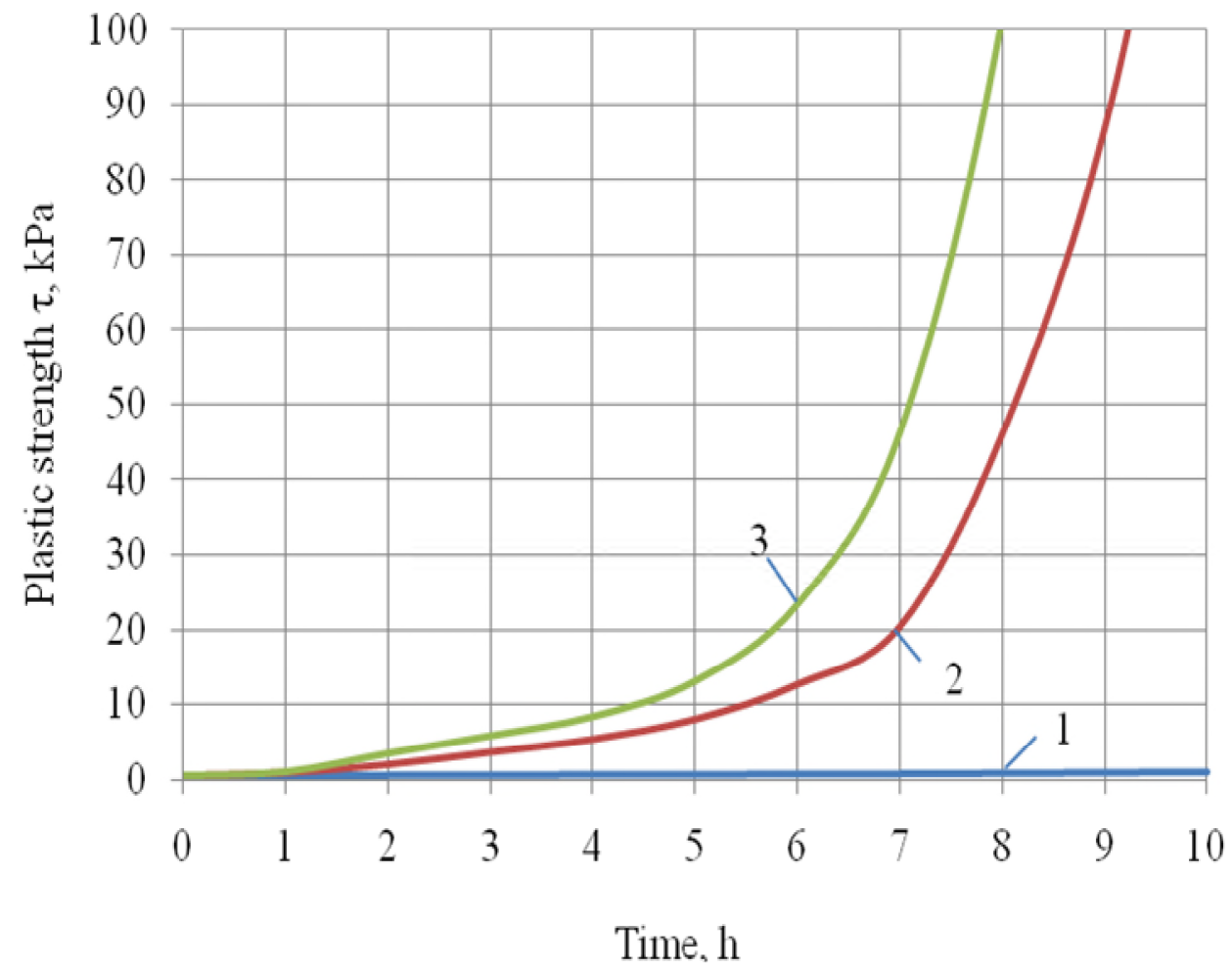

Fig. 3 Change the strength of the plastic limy mixture, $\mathrm{W} / \mathrm{L}=1$ : 1 - a control composition on limy binding material; 2 - composition with modifying additive based on a mixture of calcium silicate and aluminum silicates; 3 - Composition with the additive of aerated concrete and modifying additive based on a mixture of silicate and calcium aluminum silicates.

The introduction of the modifying additive based on a mixture of calcium silicate and silicaalumina provides a mixture of lime, characterized by an accelerated set of plastic strength. The plastic strength of control composition after 6 hours of mixing is $\tau=0,61 \mathrm{kPa}$ (Fig. 3, Curve 1), the composition with the addition of modifying additive based on a mixture of calcium silicates $\tau=$ $12,71 \mathrm{kPa}$ (Fig. 3, Curve 2 ). When add $20 \%$ of the ground aerated concrete of plastic strength after 3 hours after mixing is $\tau=23,56 \mathrm{kPa}$ (Fig. 3, curve 3 ).

The results of these studies suggest, that the use of aerated concrete in limy composition improves compressive strength. Compressive strength on samples with modifying additive based on calcium hydrosilicates and aluminosilicates mixture after 28 days air-dry hardening is Rcst $=2.48$ $\mathrm{MPa}$, and samples with aerated concrete and modifying additive based on a mixture of hydrosilicates and calcium aluminosilicate - Rcst $=2.76 \mathrm{MPa}$. Control samples (no aerated concrete 
and modifying additive based on a mixture of hydrosilicates and calcium aluminosilicate) had compressive strength - Rcst $=0.86 \mathrm{MPa}$.

The finishing composition (comprising hydrated lime, white cement, ground aerated concrete, hollow glass microspheres, an additive based on a mixture of Hydrosilicates and calcium aluminum silicates, plasticizers Melflux 2651F, redispersible powder VINNAPAS $8031 \mathrm{H}$, water repellent sodium oleate) has a high water-holding capacity, equal to $98.8 \%$, adhesive strength $\mathrm{Rad}=0.65$ $\mathrm{MPa}$. The composition has good workability, the quality of the resulting coating is characterized by a class $\mathrm{Y}$ in accordance with GOST 9.032-74, which meets the requirements of regulatory documents $[9,10]$.

\section{Conclusion}

Established, the introduction of aerated concrete increases the strength of lime composites. The introduction of the modifying additive based on a mixture of calcium silicate and silica-alumina provides a mixture of lime, characterized by an accelerated set of plastic strength.

It was found, that proposed composition of the limy dry building mixes (DBM) and coatings based on it have a high technological and operational properties and can be used to finishing aerated concrete surfaces.

\section{References}

[1] K. Wen-Yih, J. Huang, C. H. Lin, Effects of organo-modified montmorillonite on strengths and permeability of cement mortars, Cem. Concr. Res. 36 (2006) 886-895.

[2] L. Ventolà, M. Vendrell, P. Giraldez, L. Merino, Traditional organic additives improve lime mortars: New old materials for restoration and building natural stone fabrics, Constr. Build. Mater. 25 (2011) 3313-3318.

[3] V. I. Loganina, L. V. Makarova, R. V. Tarasov, E. R. Akzhigitova, Mineral Additive Based on the Mixed-Layer for Dry Construction Mixes. Contemp. Eng. Sci. 7 (2014) 1547-1554.

[4] V. I. Loganina, L. V. Makarova, Y. P. Skachkov, N. Adilova, Organomineral Additive for Dry Mixes, Res. J. Appl. Sci. 11 (2016) 294-299.

[5] V. I. Loganina, L. V. Makarova, R. V. Tarasov, K. A. Sergeeva, Increase water resistance decorative coatings on the basis of calcareous dry building mixtures, Adv. Mater. Res. 1078 (2015) 171-173.

[6] V. I. Loganina, L. V. Makarova, R. V. Tarasov, O. A. Davydova, Limy finishing compositions with the use of additive based on sol of silicon acid. Appl. Mech. Mater. 707 (2015) 81-84.

[7] V. I. Loganina, S. N. Kislitsyna, M. V. Frolov, Addition on the Basis of Mix of the Synthesized Hydrosilicates of Calcium and Aluminosilikates for Dry Building Mixtures. Proc. Eng. 150 (2016) 1627-1630.

[8] V. S. Lesovik, L. H. Zagorodnuk, I. L. Chulkova, Law affinity structures in materials. Basic Res. 3 (2014) 267-271.

[9] Guidelines for exterior finishing of walls of cellular concrete blocks autoclaved. 1 edition. Belgorod. : National Association of autoclaved aerated concrete, 20103.

[10] STO 501-52-01-2007. Design and construction of shells of residential and public buildings with the use of cellular concrete in the Russian Federation. Part 1. Introduction. 25. 01. 2007. Moscow.: Builders Association of Russia, 2007, pp. 30. 